\title{
UM ESPAÇO PARA O DESENVOLVIMENTO INTERPESSOAL NO TRABALHO
}

\author{
Rosângela Rocio Jarros Rodrigues* \\ Rosy Yuri Imai \\ Wanessa de Freitas Ferreira"
}

\begin{abstract}
RESUMO. Este é o relato da experiência de um estágio curricular na área de Psicologia Organizacional e do Trabalho, realizada numa instituição pública. O objetivo era criar um espaço no local de trabalho para tratar de temas que possibilitassem o desenvolvimento interpessoal dos indivíduos, como: autoconhecimento, relacionamento interpessoal, educação permanente e qualificação profissional, saúde e trabalho, tempo livre e aposentadoria. Foram compostos três grupos de funcionários do nível operacional e foram realizados seis encontros com cada um, ao longo do ano letivo de 2000 . Os relatos dos participantes indicam que os encontros foram produtivos para o desenvolvimento interpessoal.
\end{abstract}

Palavras-chave: desenvolvimento interpessoal, Educação e trabalho, Psicologia do Trabalho.

\section{A SPACE FOR INTERPERSONAL DEVELOPMENT AT WORK}

\begin{abstract}
This paper consists of the report of an experiment on organizational and working psychology with on probation workers of a public institution. The experiment consisted in the creation of a space at work that would propitiate the discussion of themes related to interpersonal development such as self-consciousness, interpersonal relationships, permanent education and professional qualification, health and work, free time and retirement. Three groups of workers of the operational area were formed and there were six meetings throughout the year 2000. The reports of the informers indicate that the meetings have enhanced the workers' interpersonal development.
\end{abstract}

Key words: interpersonal development, education and work, work psycology.

\section{INTRODUÇÃO}

Atualmente o mais importante não é obter um emprego duradouro, mas tornar-se empregável, mantendo-se competitivo em um mercado de mutações. A empregabilidade "é o conjunto de competências e habilidades necessárias para uma pessoa manter sua colocação dentro ou fora da empresa. (...) o profissional tem que estar atento às mudanças e se adaptar a elas", conforme Chiavenato (1997, p.85). Então, quais mudanças estão ocorrendo no mundo do trabalho e qual o perfil profissional esperado?

Inúmeras transformações estão ocorrendo no mundo do trabalho. Na era da globalização ocorrem acelerado desenvolvimento tecnológico, gerando automação das tarefas e dos serviços. A forma de organização do trabalho passa por alterações significativas, como a ênfase no modo de gestão participativo e nas células para produção dos grupos. Também nas condições de trabalho constatam-se mudanças, com a flexibilização dos horários e dos

Docente da Área de Psicologia Organizacional e do Trabalho do Depto de Psicologia Social e Institucional da Universidade Estadual de Londrina.

Endereço para correspondência: Universidade Estadual de Londrina, CCB - Departamento de Psicologia Social e Institucional, Campus Universitário - Caixa postal 6001, CEP 86.051-990 - Londrina/Pr.

\# Formandas do Curso de Psicologia da Universidade Estadual de Londrina. 
espaços de trabalho. O local de trabalho, em alguns casos, tem-se deslocado para o espaço da casa dos trabalhadores, um pouco em virtude da terceirização dos serviços. Algumas profissões estão sendo extintas e outras novas surgem. Fala-se no fim do emprego e no aumento dos índices de desempregados no país de tal forma que, hoje a palavra de ordem é que cada sujeito deve investir na empregabilidade pessoal.

As novas políticas de gestão de pessoal delineiam o novo perfil de sujeito empregável. Para Lima (1995) o perfil traçado revela a contradição e a incompatibilidade dos comportamentos entre si, como: ser competitivo e ao mesmo tempo cooperativo, individualista e capaz de trabalhar em equipe, tomar iniciativa e conformar-se às regras,etc.

Busca-se, através das políticas de gestão de pessoal, seduzir o sujeito a se adaptar ao trabalho e a comprometer-se nas dimensões que compõem o ser biopsicossocial, conforme Lima (1995). Seja qual for o nível ocupacional dos sujeitos, do gerencial ao operacional, todos são chamados a atuarem de forma ativa, criativa e crítica.

Os sujeitos que estão empregados em empresas estatais vivem os reflexos das transformações, as exigências do novo mercado de trabalho formal, e são impelidos a buscarem outro perfil, mais flexível. A demanda de estar empregável é real nestas empresas porque ali se observa o movimento do Estado em enxugar e reduzir o quadro de vagas de trabalho. A estabilidade no emprego, que era prerrogativa do setor público, é retirada pela alteração da sua legislação e a política de desvalorização do sujeito é visível através do achatamento dos salários e das precárias condições de trabalho, evidenciadas na diminuição da quantidade e da qualidade dos materiais de consumo e da manutenção e compra de equipamentos, o que leva muitos a procurarem outras empresas para trabalharem.

As empresas estatais apresentam, em sua estrutura, uma especificidade que lhes confere uma distinção nítida das empresas privadas. Elas, como outras quaisquer, possuem sua função produtiva, mas assumem contornos do Estado. Sua estruturação sempre será regida pelos planos políticos e econômicos do governo a que estão vinculadas.

Motta (citado por Lima, 1994) aponta para a centralização do poder pelo governo (federal, estadual ou municipal) e para a falta de autonomia por ele imposta. Assim, os objetivos das empresas estatais ficam sendo fixados por uma autoridade externa, e aqueles que dirigem a empresa têm dificuldade em saber o que deve ser feito e como deve ser feito, pois não são autônomos para definirem os meios e os recursos financeiros, humanos e materiais necessários ao funcionamento da mesma.

Todavia, também a este sujeito que trabalha numa empresa estatal não basta apenas o saber fazer, a conquista da competência técnica para executar a tarefa ou para exercer a função, a conclusão de cursos específicos para a formação profissional e de seus correlatos, como o domínio de outros idiomas e da computação. A empregabilidade engloba tanto a dimensão técnica quanto a interpessoal.

A competência interpessoal passa a ser um requisito imprescindível a todos os níveis ocupacionais de uma empresa, desde aquele que atende à comunidade externa à empresa como aos clientes e ao público em geral, até aqueles que convivem diariamente com o público interno, no mesmo setor (os colegas e a chefia imediata) e intersetores.

Segundo Moscovici (1985, p.27), “a competência interpessoal é a habilidade de lidar eficazmente com as relações interpessoais, de lidar com outras pessoas de forma adequada às necessidades de cada uma e às exigências da situação". Perceber de forma acurada uma situação e suas variáveis permite que o sujeito desempenhe melhor o seu trabalho, tanto na dimensão técnica requerida pela natureza dessa atividade quanto na de ser capaz de se posicionar de forma habilidosa na rede de relações interpessoais, interna e externa, no local de trabalho.

A competência interpessoal é revelada na relação indivíduo-indivíduo e nas relações indivíduo-grupo(s), englobando assim atitudes individuais e coletivas que jamais são indissociáveis. É na interação com o outro que a percepção da realidade e das suas variáveis serão introjetadas, pois "educa-se através do trabalho, através da convivialidade, do relacionamento informal das pessoas entre si” (Saviani, 1994, p.158).

A forma como o sujeito lida com a realidade organizacional e como se posiciona frente às atuais transformações e exigências do trabalho estão relacionadas com a educação vivida. A educação não formal na empresa pode servir para promover o desenvolvimento interpessoal dos sujeitos no próprio local de trabalho. Uma possibilidade viável é através de um espaço coletivo de discussão acerca das variáveis e dos conteúdos presentes nas relações intra e extragrupo.

Segundo Dejours (1994, p.136), é necessário abrir um espaço público interno de discussão que vá além do conhecimento técnico e da divisão de trabalho, "onde o trabalhador possa discutir as regras de consenso para trabalhar em conjunto e a elaboração das relações de confiança entre trabalhadores". 
Grupos de discussão em que os sujeitos apresentam as expectativas, determinam os objetivos, as necessidades e os conteúdos a serem tratados definem a ordem das atividades e estabelecem uma relação, direta e/ou indireta, do que é discutido com sua vida laboral, familiar, social e educacional.

Transformar regras, conceitos e limites no trabalho somente é possível através da construção coletiva dos sujeitos, num espaço em que o propósito seja o de obter uma nova forma, mais saudável, de organização da ação, da expressão e do comprometimento dos envolvidos.

\section{METODOLOGIA}

Este trabalho foi desenvolvido numa instituição pública vinculada à Secretaria de Estado da Agricultura e do Abastecimento do Paraná, fundada em 1972, com sede em Londrina/Pr. Possui mais dezoito estações experimentais distribuídas pelo Estado e dois pólos regionais de pesquisa. A ela foi atribuída a responsabilidade de toda a pesquisa agrícola do Paraná, incluindo-se aí as áreas de produção vegetal, animal e de recursos naturais renováveis.

Conta com aproximadamente 1.040 funcionários, distribuídos pelos seguintes cargos: agente de apoio à pesquisa, auxiliar de pesquisa, pesquisador, advogado e analista em Ciência e Tecnologia.

A demanda para a realização deste trabalho originouse de uma pesquisa realizada por Tramontina e Carizio (1999), nesta mesma instituição, acerca do uso do tempo livre, na qual foram obtidos indicadores para intervenção na área de desenvolvimento de pessoal.

Nesta instituição é desenvolvido o P.E.A - Programa de Educação de Adultos, que trata da formação dos funcionários para a conclusão do ensino médio regular. A partir desta população que está matriculada no P.E.A foram constituídos três grupos de funcionários (agentes de apoio à pesquisa) oriundos dos setores operacionais: zeladoria, creche, restaurante, vigilância, campo e laboratórios. Estes funcionários desenvolvem atividades que são realizadas em grupo e atendem à comunidade interna da instituição (os pesquisadores, a administração e o setor operacional) e ao público externo (visitantes, profissionais).

Cada grupo tinha em média vinte e duas pessoas; os três grupos somavam sessenta. A faixa etária oscilava de 30 a 69 anos. A maioria eram casados e com filhos. O tempo de permanência na instituição variava de 16 a 25 anos, todos admitidos por concurso público.
A participação era voluntária e os encontros ocorriam no horário de trabalho, com a duração de três horas aproximadamente. Para o chamamento dos interessados foram divulgados nas salas de aula do P.E.A a proposta dos encontros e os objetivos que se buscavam alcançar.

O objetivo geral do trabalho era criar um espaço para discutir coletivamente com os funcionários temas que pudessem contribuir para o desenvolvimento interpessoal dos mesmos. Através deste espaço buscava-se promover: a) a oportunidade para aprender a receber e dar feedback; b) uma atmosfera de confiança e aceitação; c) a análise dos modelos de comportamentos; d) a aplicação dos conteúdos para a vida, do sujeito dentro e fora do trabalho.

Ao longo do ano de 2000 foram realizados seis encontros com cada grupo. Os conteúdos trabalhados foram: 1) autoconhecimento; 2) relacionamento interpessoal; 3) comunicação interpessoal; 4) educação permanente e qualificação profissional; 5) saúde e trabalho e 6) tempo livre e aposentadoria. $\mathrm{Na}$ seção Resultados estão indicados os procedimentos de ensino e os conteúdos específicos de cada encontro.

A metodologia de ensino abrangeu atividades grupais e individuais, com material de apoio, como: texto impresso, recortes de revistas, cartazes. As técnicas de dinâmicas de grupo propiciaram um canal de comunicação efetivo para a integração dos participantes e para o desenvolvimento dos conteúdos. Partiu-se dos pressupostos e das práticas da andragogia para trabalhar com os grupos, formados especialmente por adultos, o que tornou possível o autodiagnóstico e a negociação mútua, a autodireção do sujeito, uma aprendizagem centrada nos problemas e nas tarefas desenvolvidas.

Alguns profissionais da instituição foram inseridos no processo, uma psicóloga e uma assistente social: uma no encontro sobre o tema educação e qualificação profissional, e a outra no tema relacionamento interpessoal. As estagiárias de Psicologia se responsabilizaram pelos demais temas e pela coordenação dos grupos.

Ao final de cada encontro foram realizadas avaliações de reações dos participantes. Concomitantemente, as estagiárias registravam as observações pessoais quanto ao processo de desenvolvimento do grupo. No último encontro realizado também se procedeu à avaliação geral.

\section{RESULTADOS}

O primeiro encontro teve como objetivo levantar as expectativas do grupo com o trabalho, conhecer os 
temas que gostariam de discutir, apresentar a proposta do trabalho e a metodologia de ensino, realizar a caracterização dos participantes do grupo, o contrato psicológico e o estabelecimento do vínculo com os participantes. Para isto utilizou-se de técnicas de dinâmica de grupo que visavam inicialmente a descontração, depois a integração dos participantes e das coordenadoras dos grupos, e por último cada participante elaborou uma colagem, com recortes de revistas, através da qual pudessem expor algumas características pessoais. Foi abordada, então, a importância do autoconhecimento para que cada um possa se perceber melhor nas interações com os outros.

O segundo encontro iniciou-se com dinâmicas de grupo que visavam ao aquecimento do grupo e à incentivação para o tema. Tratou-se de dar continuidade à exposição das colagens e foi apresentado o texto sobre a "Janela de Johari", segundo Moscovici (1985). O grupo foi dividido em quatro subgrupos, que discutiram o texto, verificando como isto se relacionava com o autoconhecimento e com o conhecimento pelo outro de nós mesmos, o relacionamento interpessoal.

$\mathrm{O}$ terceiro encontro teve como tema o relacionamento interpessoal, mas o enfoque foi na comunicação interpessoal, em dar e receber feedback. Foram utilizados como técnica de incentivação para o assunto os quadrados de cooperação apresentados por Fritzen (1981). Neste encontro houve a participação da assistente social, que relatou os resultados de sua pesquisa acerca da importância do relacionamento humano no trabalho.

O quarto encontro abordou o tema "Educação permanente e a qualificação profissional". Além das dinâmicas iniciais foram entregues aos subgrupos recortes de revistas que enfocavam mudanças que estavam ocorrendo no mundo do trabalho (flexibilização de horários, benefícios sociais, empresa e ecologia, racismo e preconceito, a ação sindical nos dias de hoje) e as suas implicações para a educação e a qualificação profissional. A psicóloga da instituição explicou a importância da educação permanente, a educação para o trabalho e a educação para a vida.

A saúde e o trabalho foram o foco central do quinto encontro, que abordou o "streess" e sua relação com o trabalho. Foi elaborado um texto, para ser discutido em subgrupos e depois em plenário, acerca do conceito de "stress", as causas (pessoais, grupais, relativas às tarefas e organizacionais), as manifestações e as implicações para a saúde geral do trabalhador.
O último encontro objetivou levar os participantes a refletirem a respeito do uso do tempo livre hoje, sobre a centralização da vida no trabalho e a aposentadoria (a ruptura com o mundo do trabalho e com a identidade profissional).

\section{DISCUSSÃO}

Durante as primeiras intervenções os participantes não tinham conhecimento sobre o que poderia ser tratado através da Psicologia. Inicialmente os encontros foram entendidos como mais uma aula ligada ao P.E.A. Alguns entendiam como um momento de brincadeira, por causa das dinâmicas de descontração, reproduzindo a idéia de que para se ser sério tem que estar dentro do modelo formal e bancário de educação e de trabalho. Revelando a crença de que sempre se deve produzir algo concretamente, aí a dimensão subjetiva não encontra espaço para ser expressa.

Algumas pessoas começaram a perceber o espaço como um momento importante para apresentarem reivindicações, como aumento de salário, de contratação de pessoal, de cursos de treinamento de pessoal. Estas questões foram ouvidas e discutiu-se a viabilidade de cada uma, por quais canais e quais instâncias institucionais e governamentais. Isso fortaleceu a confiança dos participantes em relação à proposta dos encontros, pois não foi impedida a fala em relação a aspectos críticos do trabalho, dentro da instituição. Segundo Dejours, este espaço é necessário para que se estabeleçam as regras de consenso entre os trabalhadores, e relações de confiança.

Nas dinâmicas que incentivavam o grupo para a exposição dos temas, os participantes encontram certa dificuldade em extrapolar o que foi vivenciado para a realidade profissional e pessoal. No decorrer dos encontros foram constatadas algumas mudanças neste sentido, aos poucos a proposta dos encontros foi se tornando mais clara e eles se tornaram ricos espaços de discussões e expressividade de sentimentos, angústias, temores e preocupações. As pessoas envolvidas começaram a perceber o espaço como algo deles, determinado pelas contribuições que cada um poderia dar, pela atenção prestada em ouvir o outro, mesmo quando apresentavam um pensamento ou uma opinião contrários aos seus. Tornou-se um espaço de dar e receber feedback e com relatos de mudança de comportamentos frente a situações internas e externas ao trabalho.

Os participantes passaram a dar significado próprio para a desenvolvimento pessoal e interpessoal, entendendo que a educação vai além do ambiente 
formal de trabalho e da preparação técnica, e identificaram a importância do investimento pessoal na qualidade de vida, sem esperar que o Estado faça isso por eles ou que possam creditar ao mesmo a razão do seu sofrimento, pois na verdade eles são sujeitos também da sua história.

Um participante relatou: "nos primeiros encontros eu não conseguia falar, eu tremia todo. Se tinha que falar alguma coisa com o chefe, eu não conseguia, ficava tremendo, nervoso. Hoje eu vou e falo, até falo algumas reivindicações".

A última avaliação geral feita demonstrou que os encontros foram bons, que atenderam às expectativas, mas que poderiam ser dados com carga horária mais longa, que deveriam ser estendidos a outros, na instituição, de forma que pudessem abranger também as chefias setoriais, a fim de serem obtidos resultados mais eficazes.

\section{CONCLUSÃO}

A organização se constitui numa rede de relações tecidas por indivíduos dotados de idéias, necessidades e sentimentos que estão, a todo o tempo, presentes nas interações sociais, refletindo como estes indivíduos percebem e vivenciam a realidade.

A realização deste trabalho permitiu desenvolver uma proposta inspirada no modelo dejouriano de espaço da fala e observar os participantes manifestando desejos, necessidades, emoções, ansiedades, frustrações, medos, insatisfações e expectativas que estão no cotidiano de cada um. As organizações devem atentar para esta demanda que tem surgido, pois o novo perfil do profissional, preconizado pela empregabilidade, há de ser mais crítico, criativo, ativo e, concomitantemente, mais reivindicativo, seja no setor público ou privado.

\section{REFERÊNCIAS BIBLIOGRÁFICAS:}

Chiavenato, I. (1997). A corrida para o emprego. São Paulo: Makron Books.

Dejours, C.; Abdoucheli, C.; Jayet (1994). Psicodinâmica do trabalho: Contribuições da Escola Dejouriana à análise da relação prazer, sofrimento e trabalho. São Paulo: Atlas.

Fritzen, S. J. (1981). Exercícios práticos de dinâmicas de grupo. Rio de Janeiro:Vozes.

Lima, M.E.A.(1995). Os equívocos da excelência: Novas formas de sedução na empresa. Rio de Janeiro: Vozes.

Lima, S.M.L. (1994). Definição e implementação de objetivos nas organizações públicas de saúde. Revista de Administração Pública 28 (4), 38-64.

Moscovici, F. (1985). Desenvolvimento interpessoal. (3 ${ }^{\text {a }}$ ed., Rio de Janeiro: LTC.

Saviani, D. (1994). O trabalho como princípio educativo frente às novas tecnologias. Em C.J. Ferreti e cols. (Orgs.) Novas tecnologias, trabalho e educação: um debate multidisciplinar. São Paulo: Makron Books.

Tramontina, V.M. ; Carizio, W.G. (1999). Trabalho e tempo livre. Relatório de estágio. Curso de Psicologia da Universidade Estadual de Londrina.

Recebido em 01/02/2001

Revisado em 20/06/2001

Aceito em 30/06/2001 